\title{
Agile Planning Processes
}

\author{
Ralph Riedel, David Jentsch, Sebastian Horbach, \\ Joerg Ackermann, and Egon Müller \\ Chemnitz University of Technology, Department of Factory Planning \\ and Factory Management, Chemnitz, Germany \\ \{ralph.riedel, david.jentsch, sebastian.horbach, \\ joerg.ackermann, egon.mueller\} @mb.tu-chemnitz.de
}

\begin{abstract}
The paper explores the requirements and support systems for agile planning processes. It reviews therefore traditional planning processes and proposes a new model based on agile principles. The novel planning model is employed to frame a component-based planning approach and its application in a planning manual.
\end{abstract}

Keywords: Agility, component-based planning, planning methods.

\section{Introduction}

Production systems are decisive for the competitiveness of industrial enterprises and major characteristics of these systems are determined during their planning phase. Both, production systems and production system planning are embedded in a dynamic and complex environment, which is shaped by tremendous changes like higher market dynamics and the awareness for scarce resources. New system characteristics like modularity and adaptability [1] are needed in response. Together with further trends e.g. in IT, resulting production systems become more and more complex and less predictable.

Resulting challenges cannot be met with the traditional planning approaches. New methods are required to cope with uncertainty, dynamics and complexity [2]. Agile principles were developed for software development to meet exactly these challenges. This paper absorbs these agile principles and transfers them to the process of production system planning.

The remainder of the paper is organized as follows: The following chapter briefly summarizes production systems in general, the particularities of production system planning, as well as agile principles. Concluding requirements for new planning approaches are derived. The third chapter provides the novel agile planning model. This is followed by the description of a concrete idea of realization, the modular planning methodology and of a supportive tool, the interactive planning manual. The paper concludes with directions for further research. 


\section{Theoretical Background}

\subsection{Production Systems}

The notion of production systems is based on general systems theory [3] and the fundamental views on systems [4]: the structural, hierarchical and functional perspective [5]. The structure includes people, technology and organization, while the hierarchy denotes several layers from the individual workplace up to the network of production facilities [6]. The function highlights that the system transforms inputs into value added outputs due to an open system border and processes (operational, management and supportive processes).

\subsection{Production System Planning}

The core task of production system planning, namely factory planning [7], is the design, dimensioning, realization and ramp-up of production sites [8]. Due to its uniqueness, production system planning is usually executed as a project and is primarily oriented on the business objective of ensuring a strong competitiveness [9]. There is a high degree of uncertainty in early stages of the planning process whereas this decreases throughout the planning project. Therefore, a systematic procedure is recommended in order to cope with the existing complexity [8]. A common generic procedure for problem solving is the systems engineering method, which consists of the steps (1) searching for and setting goals, (2) searching for solutions and (3) selecting a suitable solution [10]. Most of the phase models for production system planning are based on this logic.

The majority of methods used in production system planning can be characterized as analytical, which qualifies them for deterministic and static situations as well as for long-term planning cycles [11]. The usage of these methods follows a simple stimulus-response scheme (problem - method - solution) which does not reflect the actual understanding of a problem [12]. Therefore, conventional planning principles are more and more limited in a complex and turbulent environment.

Production systems (and also planning systems) can be described with typical characteristics from general systems theory: They are emergent, i.e. the behavior of the system can be predicted from the behavior of the single elements, which are the different protagonists and stakeholders in a planning project. They are cross-linked, i.e. the particular elements (protagonists, activities, decisions) are dependent on each other. They are contingent, i.e. the relations between the particular elements cannot be determined a priori but emerge in the course of execution. They are open, i.e. there is an exchange with the relevant environment, which in turn can be characterized as fuzzy and dynamic. They are complex, i.e. a huge amount of elements and relations and their dynamics lead to a high amount of possible alternatives for behavior (high variety). They are self-referential, i.e. the behavior of the system has effects on the system itself. They are (partly) autonomous, i.e. the system can independently make decisions regarding its own activities. 


\subsection{Agility and Advanced Planning Methods}

Agile principles emerged first in software development projects and were established to overcome the traditional plan driven methods, e.g. the waterfall model or the spiral model [13,14]. The agile principles are documented in the Agile Manifesto [15] (see also $[14,16])$ and comprise values like "Individuals and interactions are more important than processes and tools" or "Responding to change is more important than following a plan". Agile methods can be characterized as follows [14, 17]:

- Iterative: they deliver full functionality from the very beginning and then change it with each new release

- Incremental: the system is partitioned into small subsystems by functionality and new functionality is added with each new release

- $\quad$ Self-organizing: the development team has the autonomy to organize itself

- $\quad$ Emergent: technology and requirements emerge throughout the development process

Augustine et al. [13] characterize the agile approach as an "overall humanistic problem solving approach", which assumes that all members are skilled and valuable stakeholders relying on the collective ability of autonomous teams as the basic problem-solving mechanism and minimizing up-front planning. The adaptability to changing conditions is stressed instead. Agility does not mean that there is no planning. Conversely, there is no detailed pre-determination of the whole project activities at the beginning. Planning is done phase by phase and is understood as a continuous process, which adapts to the ever changing situation [18].

\subsection{Implications and Requirements for Planning Processes}

The process of production system planning can be defined as a problem solving process for complex, ill-defined problems. Typical characteristics of such problem situations are a small amount of transparency, multiple and contradictory objectives, a vast number of interrelated influencing factors, fuzziness and uncertainty. As a result, it is hardly possible to oversee all relevant factors, interrelations and the problem as a whole from the very beginning. A clear picture can be developed only when working on the problem and when gaining more and more knowledge about the situation and about the system.

A central requirement from this discussion is that planning processes and the underlying activity sequences must be able to cope with insecure and incomplete information and goal definitions. Further information is gained in the course of working on the planning project. With more and more detailed information, the activity plan as well as used methods and tools can be concretized. Furthermore, a common issue is the unreflected usage of methods and tools ("methodism"). Solving this problem requires the evaluation of the suitability of methods for each situation and to allow necessary adoptions. 


\section{$3 \quad$ Agile Planning Model}

\subsection{Process Model}

For the subject area of production systems planning, which is characterized by a high degree of complexity and dynamics, it is barely possible to determine all necessary steps and activities in advance in a detailed manner. It is rather necessary to adapt the planning procedure to the actual situation. Therefore, the planning of activities becomes more and more accurate when eligible information becomes available in the course of the project execution. The activity plan itself cannot be considered as finalized but needs to be adapted during the whole project. This procedure is known as "planning on the road" or as "planning construction site" $[19,20]$. Transferring this principle to production system planning relates back to the agile approaches and the resulting procedure is displayed in figure 1 [cf. 21].

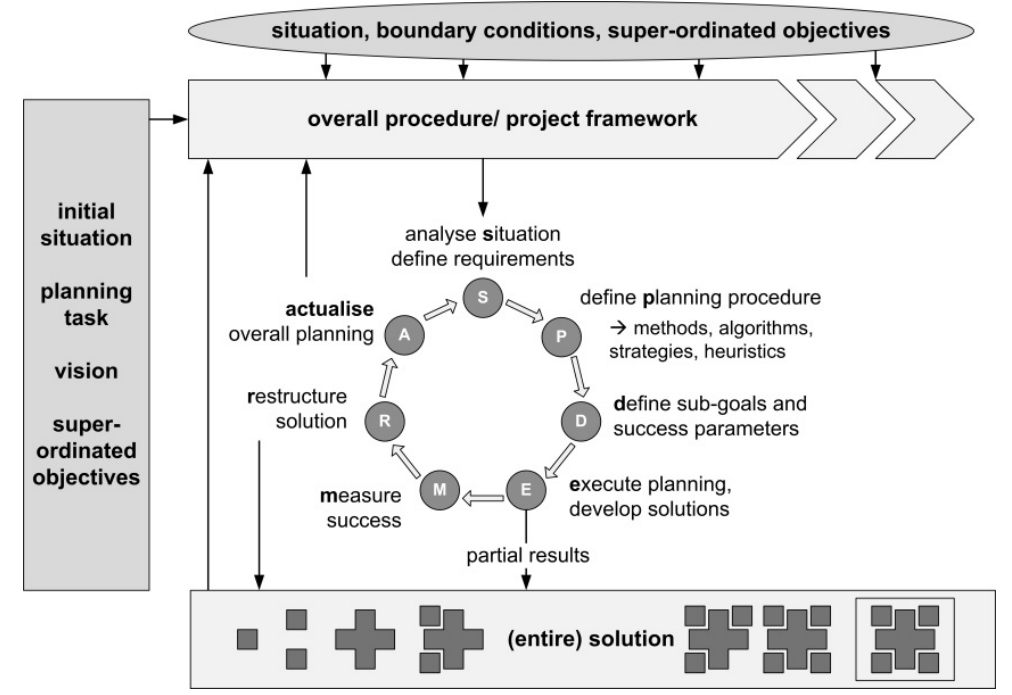

Fig. 1. "Planning on the road"-principle

Based on a problem definition, objectives and a vision for the planning project are developed. Hereby it has to be considered that objectives may change during project execution due to external developments or due to knowledge gained as the project progresses. Then a framework is defined based on objectives and identified boundary conditions. The expected result is specified as far as possible. For the execution, this framework needs to be detailed - but only as far as reliable information allows. Activities which are close to the point of time when the planning is carried out can be specified better than activities with a greater temporal distance.

This is followed by executing the project, whereas - following the procedure of a continuous improvement process - the following steps are processed in terms of several iterations: 
- Analysis of the situation, i.e. of environment, requirements, goals, actual results, system behavior and system performance etc.

- $\quad$ Fixation of an appropriate procedure/ development of an activity plan for the next steps; hereby the procedure is concretized stepwise while executing the planning project

- Definition of sub-goals consistent with the overall goals of the project

- $\quad$ Execution of the activities, i.e. of particular planning steps

- $\quad$ Evaluation of results, based on pre-defined success criteria

- Restructuring of the entire solution/ concept, based on the insights gained whilst performing the activities

- $\quad$ Actualization of the overall planning procedure

The advantage of this procedure is that intermediate results can be gained, which are tangible, and the results can be evaluated against initially defined goals. At the same time, internal and external dynamics are considered due to the iterations. Therefore, the project planning as well as the whole planning project can be labeled as evolutionary. The effects of the proposed procedure are shown in figure 2.

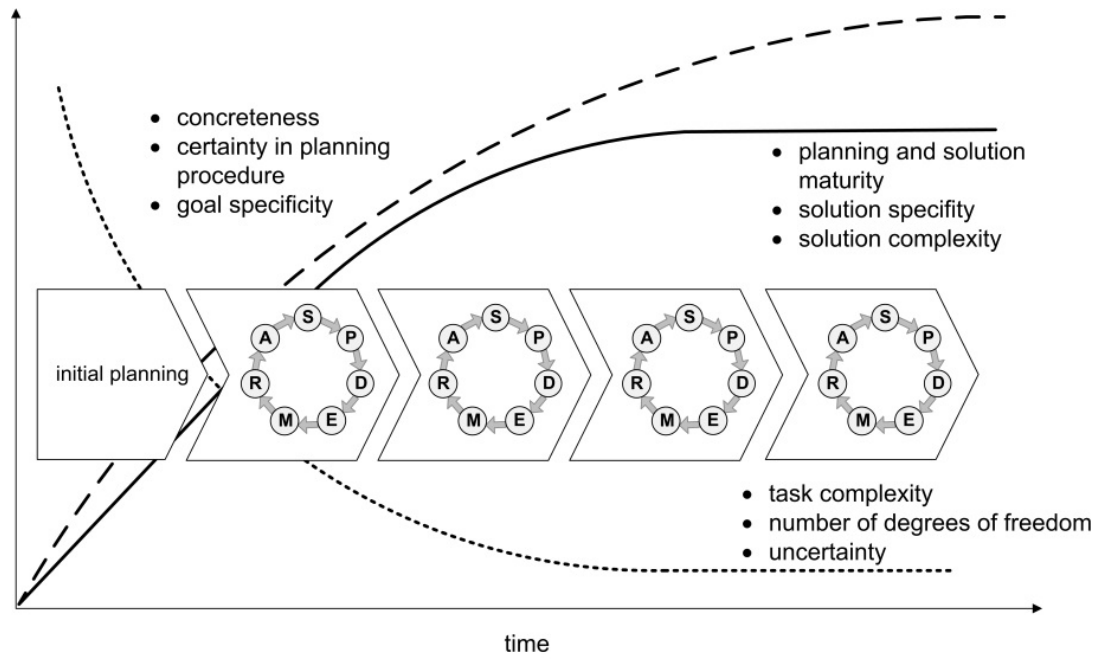

Fig. 2. Project and solution maturity development

On the one hand the uncertainty might be rather high at the beginning of a planning project. On the other hand the degrees of freedom for the later solution and the possibilities for variations are high as well. This is equivalent to a high degree of complexity [22]. Therefore, the concreteness and specificity of goals needs to be low in order to allow enough degrees of freedom for planning activities and for the later solution. This corresponds to a high degree of internal variety which fulfills the "law of requisite variety" by Ashby [23]. With an increasing degree of maturity, i.e. progress in the planning project, uncertainty is reduced, and the complexity of the task and internal variety are decreasing. As a consequence, the degrees of freedom for activities and for 
the solution are reduced. However, the complexity of the solution increases because intermediate solutions and sub-systems as well as their interrelations are fixed.

The described model could be summarized as reference on how agile planning processes are designed. This leaves a gap on the actual planning content which is further elaborated in the next section.

\subsection{Component-Based Planning as Content Model}

One possibility to model the planning content can be found in component-based planning, dating back to the 1970s, when Wirth and Zeidler [24] developed the vision of functional elements (components) in a modular system allowing for combination of components and their reuse across planning projects. This line of thought yielded two analytical classes: planning components and the particular elements of the production system: the object components (e.g. technology). Jentsch et al. [25] showed in this respect a strong dominance of object components in the planning literature, while planning components are less developed. We will therefore focus on planning components further on.

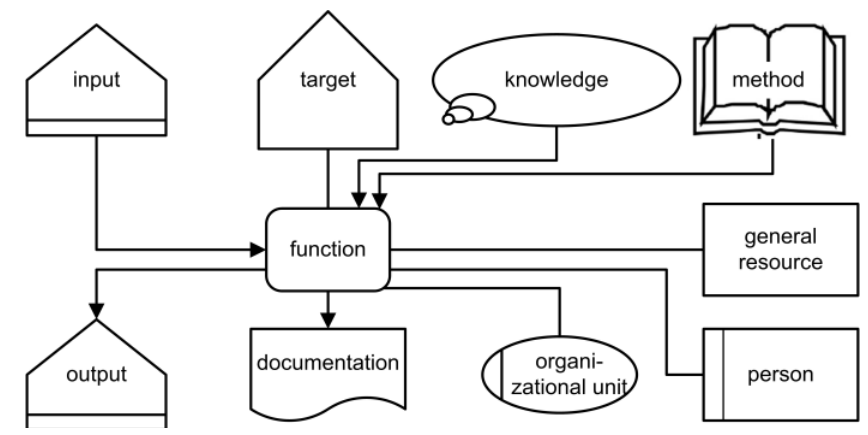

Fig. 3. General model of a planning component displayed as a function diagram (based on [26])

The concept of planning components was significantly enhanced by King-Kordi and Näser [26, 27] with the perspective of socio-technical systems and yielded the following views: The target view pertains to specific and measurable goals of a component or its deployment. Tasks or operations are represented in the functional view. A function utilizes tangible and intagible resources (people, knowledge, machinery etc.) summarized with the resource view. The structural view refers to different hierarchical layers of the production system. Finally, the yield view summarizes the (potential) output of a system in terms of products or services. Planning components can be further detailed based on this view concept (see figure 3). This generic model of a planning component distinguishes further kinds of resources such as methods and particular knowledge, which is necessary to fulfill the planning function.

The outlined component model enables the modularization of the planning process. Hence, planning components provide the generic building block to fill agile planning processes with required tasks. This could be done either with a blank-sheet-approach in every project or building upon the documentation of prior experience. The next 
section follows the second suggestion and introduces a way to access experience structured in a component-oriented manner.

\subsection{Interactive Planning Manual}

The general idea of the interactive planning manual is to support on the one hand inexperienced project members with a pool of completed planning processes. Here, the user may check e. g. how to use a specific planning tool. On the other hand, the component oriented structure allows for a simple reuse of particular building blocks by integrating them into a new planning project. Users receive consequently a bridge between task specific knowledge and its application during the planning process.

The manual follows a modular structure enabling for example the classification of the planning problem in order to find in a library suitable building blocks or combinations of them as planning processes. Further modules allow for definition of new components and processes as well as the tracking of project progress. Further details are given by Jentsch et al. [25]. The manual was implemented in a standard enterprise content management system and is currently being prepared for a laboratory test with students utilizing the manual during a long-term case study on production system planning. The test is intended to yield further insights in system acceptance and its suitability for agile planning processes.

\section{Conclusion and Outlook}

The dynamics of the environment and the complexity of modern production systems induce the requirement to reconsider planning methods. The combination of these observations with a modern understanding of human problem solving yields a new approach towards planning the production systems of the future.

However, the conceptual work on planning processes does not stand alone. There are conceptual synergies to component-based planning and those synergies will be further investigated by means of laboratory tests in the near future.

\section{References}

1. Zaeh, M.F., Moeller, N., Vogl, W.: Symbiosis of Changeable and Virtual Production - The Emperor's New Clothes or Key Factor for Future Success? In: CARV 2005, pp. 3-10. Utz, München (2005)

2. Riedel, R., Mueller, E.: Integrating Planning and Operations, Technology and People in Industrial Engineering. In: Spath, D., Ilg, R., Krause, T. (eds.) Proceedings of the 21 st International Conference on Production Research (ICPR), Stuttgart (2011)

3. von Bertalanffy, L.: An Outline of General Systems Theory. The British Journal for the Philosophy of Science I, 134-165 (1950)

4. Ropohl, G.: Allgemeine Technologie - Eine Systemtheorie der Technik. Universitätsverlag Kalsruhe, Karlsruhe (2009)

5. Bellgran, M., Säfsten, K.: Production Development. Springer, London (2010) 
6. Jentsch, D., Riedel, R., Günther, L., Müller, E.: Strategic Capabilities as Enablers for Innovation in Production Systems. In: Spath, D., Ilg, R., Krause, T. (eds.) Proceedings of the 21st International Conference on Production Research (ICPR), Stuttgart (2011)

7. Schenk, M., Wirth, S., Müller, E.: Factory Planning Manual: Situation-Driven Production Facility Planning. Springer (2009)

8. Hernández Morales, R.: Systematik der Wandlungsfähigkeit in der Fabrikplanung. VDI Verlag, Düsseldorf (2003)

9. Schmigalla, H.: Fabrikplanung: Begriffe und Zusammenhänge. Hanser Verlag, München (1995)

10. Haberfellner, R., Nagel, P., Becker, M.: Systems Engineering. Orell Füssli (2002)

11. Dombrowski, U., Hennersdorf, S.: Methoden- und Werkzeug-Matching zur Planung innovativer Fabriken: Von Betriebszielen zu innovativen Fabrikstrukturen. wt Werkstattstechnik Online 100, 234-241 (2008)

12. Dörner, D.: Problemlösen als Informationsverarbeitung. Kohlhammer, Stuttgart (1987)

13. Augustine, S., Payne, B., Sencindiver, F., Woodcock, S.: Agile projectmanagement. Communications of the ACM 48, 85-89 (2005)

14. Lindvall, M., Basili, V.R., Boehm, B., Costa, P., Dangle, K., Shull, F., Tesoriero, R., Williams, L., Zelkowitz, M.V.: Empirical Findings in Agile Methods. In: Wells, D., Williams, L. (eds.) XP/Agile Universe 2002. LNCS, vol. 2418, pp. 197-207. Springer, Heidelberg (2002)

15. Manifesto for Agile Software Development, http://agilemanifesto.org/

16. Boehm, B.: Get ready for agile methods, with care. Computer 35, 64-69 (2002)

17. Pfleeger, S.L.: Software Engineering: Theory and Practice. Prentice Hall, Upper Saddle River (1998)

18. Gernert, C.: Agiles Projektmanagement: Risikogesteuerte Softwareentwicklung. Hanser, München (2003)

19. von der Weth, R.: Die Sinnlichkeit des Wissens und die Weisheit der Dinge. In: Sachse, P., Weber, W.G. (eds.) Zur Psychologie der Tätigkeit, pp. 87-100. Huber, Bern (2006)

20. von der Weth, R.: Management der Komplexität. Ressourcenorientiertes Handeln in der Praxis. Huber, Bern (2001)

21. Riedel, R.: Systemische Fabrikbetriebsplanung auf Basis eines kybernetisch - soziotechnischen Modells. Chemnitz (2012)

22. Malik, F.: Strategie des Managements komplexer Systeme: Ein Beitrag zur ManagementKybernetik evolutionärer Systeme. Haupt, Bern (2006)

23. Ashby, W.R.: An introduction to cybernetics. Chapman \& Hall, London (1956)

24. Wirth, S., Zeidler, H.: Untersuchungen zur Entwicklung und Anwendung von Bausteinen in der technologischen Betriebsprojektierung unter besonderer Berücksichtigung ihrer Schnittparameter (1974)

25. Jentsch, D., Horbach, S., Ackermann, J., Mueller, E.: Towards an Interactive Planning Manual for Production Networks. In: XVII Summer School "Francesco Turco", Venice (2012),

http: / /www . summerschool-aidi.it/images / paper2012/3.6.pdf

26. King-Kordi, A.: Methodik zur bausteinbasierten Planung und Organisation von verfahrenstechnischen Produktionssystemen (2010)

27. Näser, P.: Component based planning of manufacturing plants. In: 3rd Annual Conference on Systems Engineering Research, pp. 393-402. Stevens Institute of Technology, Hoboken (2005) 